A publication of the Muma College of Business | University of South Florida

JEAN CHUA, STACY-ANN HENRY, DARRYL JOHNSON, GERALD MALLORY, JUSTIN SMITH, RAYMOND WILHITE

\title{
JABIL: NAVIGATING SUPPLY CHAIN UNCERTAINTY ${ }^{1}$
}

\author{
At Jabil, we have the infrastructure, scale and talent to one day become the most technologically \\ advanced manufacturing solutions company in the world, and one that's sustainable for years to \\ come. -- Mark Mondello, Jabil CEO
}

"Are we truly ready to ride this wave?" asked John Parker, Executive Vice President and Chief Executive Officer of the Jabil, Inc. (Jabil) Engineered Solutions Group (ESG). As he glared at his blurred reflection in the ocean from his fishing boat, the only thoughts that seemed to surface were those related to his upcoming strategy presentation on critical manufacturing solutions for the five market sectors in his division. Jabil's leadership team was eager to review his department's proposal on risk mitigation regarding the recent imposition of tariffs on overseas industrial goods and services that impacted his group. Parker knew his recommendations and decisions thereafter would directly impact customer retention, profitability, and the company's overall brand and reputation. How would he help Jabil remain on course in the ever-changing sea of complexity?

As Parker cast his line and waited, he reflected on the many times he had enjoyed calm seas and fair winds. The weather was truly unpredictable no matter what the forecast. Despite the inevitable irregularity of outdoor conditions, it was clear that climate was only one of the many elements to be considered. Parker thought of how this related to many of the supply chain decisions impacting the business. For instance, a sudden change in oil prices could rapidly increase shipping costs while a global recession could immediately decrease demand, negatively impacting market conditions. Parker was focused on ensuring his proposal encompassed a sound and comprehensive strategy that leveraged Jabil's advanced tools while remaining true to its values. As one of the largest global manufacturing solutions companies in the world, Jabil recorded annual revenues that exceeded $\$ 22$ billion in 2018 and maintained a vast transnational footprint totaling nearly 43 million square feet of production capacity. With almost half of its manufacturing space in China, recently imposed tariffs on Chinese imports directly impacted Parker's division, which supplied industry partners with advanced technological solutions at market competitive pricing. Would pricing negotiations and contract revisions now be necessary to retain and preserve customer loyalty? What would Parker present as a display of Jabil's capability to scale and transfer business globally without interruption for customers? Perhaps a hybrid approach would allow Parker to demonstrate Jabil's agility while servicing customers globally. One thing was clear to Parker: Jabil's advanced capabilities and global footprint uniquely positioned the company to take advantage of opportunities where competitors were challenged.

\footnotetext{
${ }^{1}$ Copyright (C) 2019, J. Chua, S. Henry, D. Johnson, G. Mallory, J. Smith, R. Wilhite. This case was prepared for the purpose of class discussion, and not to illustrate the effective or ineffective handling of an administrative situation. Names and some information have been disguised. This case is published under a Creative Commons BY-NC license. Permission is granted to copy and distribute this case for non-commercial purposes, in both printed and electronic formats.
} 


\section{Electronics Manufacturing Services}

\section{Background}

Starting around the same time Parker joined Jabil in 1999, the company became a major player in the Electronics Manufacturing Services (EMS) industry. EMS referred to companies that engineer, design, manufacture, test, and distribute electronics components and assemblies for Original Equipment Manufacturers (OEMs). Jabil differentiated itself from traditional manufacturing solutions providers through its end-to-end value-added service offerings, including product development, mechanical and electrical engineering, and testing. EMS companies manufactured and supplied products and components to upstream companies that were then sold under specific brand names. EMS companies produced individual electronics components for companies (e.g., Intel microprocessors, LG and Samsung displays, etc.) that were then supplied to the consumer-facing electronics retailers (e.g., Apple Computer, Samsung, Google, HTC, etc.) with the components necessary to create and sell the final consumer product. In some cases, the EMS company that manufactured the individual components also completed assembly of the final product that was supplied to the retailer ready to sell (Leong, 2015).

\section{History}

Prior to approximately 1975 , the manufacturing of electronics components was historically managed and completed in-house by the companies that sold products to consumers. The late 1970s gave rise to the outsourcing of the manufacture of electronics components to third-party manufacturers that supplied the labor, materials, tooling, processes and automation necessary to deliver manufactured components to the hiring entity (client). As the industry matured, companies competing in the space sought to differentiate themselves from competitors by offering value-added services and capabilities and sought to shift the industry from exclusively manufacturing to manufacturing and services. The scope of EMS historically ranged from the manufacture and supply of individual components to the client, to end-to-end product development that included the design, material procurement, manufacture, and assembly of entire products that were delivered to the client as finished goods.

\section{Modern EMS}

Historically, EMS companies did not make any of their own products and instead contracted with a customer who provided specific designs, formulas, and/or specifications that stipulated product requirements. Since the manufacturing specifications were controlled entirely by the customer, said customer was able to leverage manufacturers by soliciting multiple prices for the same products with the belief that the product would ultimately be consistent, regardless of the manufacturer selected. This landscape created tremendous price pressure among manufacturing competitors and required those manufacturing solution providers to operate sophisticated manufacturing networks to maintain competitive advantage.

Modern EMS companies looked to increase competitive advantage by offering customers a more integrated approach to manufacturing. By partnering with their customers, EMS companies sought to deepen their understanding of their customers' businesses and design products and systems to best support their customers' manufacturing needs in a more wholistic, global manner. The most successful manufacturing solution providers were those that leveraged the winning combination of operational efficiency, supply chain sophistication and redundancy, a deep understanding and anticipation of customer needs, and strong customer relationships to stay ahead of the evolving needs of their customers.

EMS and manufacturing more broadly carried inherent benefits and risks for both the client and the contract manufacturer. Outsourced manufacturing allowed customers to leverage the manufacturer's economies of scale to enhance pricing, eliminate the need for expensive in-house manufacturing by the 
client, and harness the vast expertise and resources of the manufacturer to deliver consistent, high-quality products. Manufacturing solution providers used similar equipment and processes to produce a variety of products for a variety of customers, which drove down unit operating costs for each individual contracted entity and produced recurring, predictable cost projections for the client and revenue streams for the contractor.

\section{Supply Chain and Geography}

Since they were not typically responsible for product distribution to the end-consumer, manufacturing solution providers could be somewhat geographically agnostic and established manufacturing operations in the most logistically and economically advantaged regions of the world. Although the geographically distributed nature of manufacturing allowed manufacturers to take advantage of logistical and economic advantages of specific regions around the world, it also required manufacturers to remain nimble in the way they anticipated and responded to shifts and/or disruption to their supply chains and/or manufacturing operations caused by external events. Customers expected manufacturers to maintain systems that allowed for seamless transitions of manufacturing capacity so that the client's production was not impacted by changing external conditions.

Supply chains and manufacturing processes for electronics products such as industrial equipment, consumer electronics, and mobile devices required the availability of a skilled labor force. The availability of materials, relatively low-cost availability of skilled labor, and low operating costs historically made China and southeast Asia a popular hub for companies competing in the EMS space. Because several of the world's largest EMS companies operated multiple simultaneous manufacturing sites in China, the country eventually became a global center for the EMS industry after entering the World Trade Organization (WTO) in 2001.

\section{Onshoring, Nearshoring, Emerging Markets}

Between 2006 and 2018, shifts in both the demand for consumer electronics and the geopolitical landscape caused disruption to China's hold on the EMS market. The combination of rising wages in China and rising pressures on manufacturers to reduce costs to better compete in emerging markets caused many EMS technology companies to establish new lower-cost manufacturing locations in other parts of the world. To reduce costs, technology manufacturers evaluated replacing, at least in part, the traditional long-distance, east-west supply chains with more regionally focused ones. Companies explored regionalization of the supply chain as a possible mechanism to reduce manufacturing costs, reduce latency and working capital in the supply chain, and improve customer service.

As emerging markets began to constitute a larger portion of the overall electronics market, meeting the varying demands of both mature and emerging markets made nearshoring or onshoring a portion of manufacturing a viable option for companies looking to mitigate risk, minimize transportation costs, and improve response to client needs. In addition to positioning themselves to better respond to client needs on a regional basis, diversifying manufacturing insulated EMS companies from location-specific risk. Companies with diverse, global manufacturing networks, such as Jabil, were better positioned to both anticipate and respond to external stressors on their business processes than regional companies and used such events to improve competitiveness, gain market share, and strengthen client relationships. 


\section{Competitive Landscape}

EMS companies typically fell into one of two categories with respect to supply chains: vast, complex, global supply chains that supplied global customers and regionally focused supply chains that serviced regional customers. Global manufacturers like Jabil leveraged advanced service offerings and complex networks to deliver enhanced flexibility, sophistication, and redundancy to global customers, whereas regional manufacturers focused their efforts on cost, speed, and agility within a limited footprint. Although regional EMS companies could, at times, outcompete larger companies on cost, regional manufacturers operated with an increased vulnerability to regionally specific external factors or constraints. Global manufacturers competed by operating a complex manufacturing network that used advanced services and tools and geographic diversity to mitigate risk and used the sophistication of their supply chain and manufacturing processes to find opportunity in situations where regional companies were weakened by external constraints.

\section{External Forces}

Looking up at the horizon, Parker could see storm clouds in the near distance. The strong winds coupled with the push and pull of the ocean's currents caused Parker to briefly lose his balance. As he nimbly reset his footing, Parker realized he was adept at adjusting quickly while steering the ship amid continuous change. The same could be said of Jabil, especially given its advanced seafaring capabilities. Although the imposed tariffs were just one of thousands of factors that could be deliberated in many business-related decisions, they were still poignantly significant.

\section{Tariffs}

Tariffs are taxes imposed on goods or services. Tariffs are used to restrict imports by increasing the price of goods and services purchased from overseas and making them less attractive to consumers (see Exhibit 2).

\section{History of Tariffs}

Tariffs were originally put in place to protect a nation's wealth. In the pre-modern European era, a colony's wealth was based on its tangible assets such as gold, silver and other physical resources. These resources were traded amongst other colonies and the nation's wealth was either increased or decreased based on its resources going in or out. The first tariffs were put into place to limit the reduction of wealth within the colonies by applying taxes to trades outside of the colonies.

There were two types of economic beliefs/theories in the pre-modern European era: Mercantilism and Comparative Advantage. Mercantilism relied heavily on tariffs and possible bans on trades. The thought was that colonies could harvest raw materials and produce products within the colony and trade within itself which kept the wealth within its own colony. Comparative Advantage was a slightly newer theory, beginning in the 18th century, that believed if countries could specialize in producing certain products they should, and the resulting products should be traded with other countries who specialized in other resources or products. Comparative Advantage posited that tariffs stifled growth in economies (Staff, 2017).

\section{Modern Era Tariffs}

During the 19th and early 20th century, there was a period of free trade in which Comparative Advantage was prevalent among countries. This was put to a halt, however, by heavy tariff-imposed regulations resulting from World Wars I and II. These modern tariffs were a nation's way to increase revenues and made up nearly $30 \%$ of the United States government's revenue base during this period (Staff, 2017). 
After the World Wars, the world saw another era of free trade that created institutions and agreements such as the World Trade Organization (WTO) and the North American Free Trade Agreement (NAFTA).

The World Trade Organization (WTO) was the organization that monitored and imposed international trade barriers among its 124 nations. The WTO regulated the trade of goods, services and intellectual property by providing a framework for negotiating trade agreements and resolutions to disputes. Its rules and by-laws were officially adopted on January 1, 1995 and replaced those of the General Agreement on Tariffs and Trade (GATT) that was signed by 23 nations in 1947.

The North American Free Trade Agreement (NAFTA) was the fair-trade agreement between the United States, Canada and Mexico. NAFTA replaced the Canada-United States Free Trade Agreement and was put into place on January 1, 1994. NAFTA, like many other free trade policies, was intended to eliminate barriers to trade between the U.S., Canada and Mexico (Staff, 2017).

\section{The 2018 United States' Tariffs on Chinese Goods}

In June 2018, the United States announced a change in the post war trend. The United States imposed tariffs on specific materials and goods that directly affected trade with China (see Exhibit 2). The deal imposed the restrictions with the hope that the tariffs would help US companies be less reliant on Chinese manufacturing and supply chain goods. The 2018 Tariff plan was estimated to impact approximately $\$ 150$ billion worth of Chinese goods.

As an attempt to negotiate with the United States, China agreed to increase purchase of US agriculture and energy products along with substantially reducing the United States trade deficit in goods with China. At the time, the United States recorded an annual trade deficit of about $\$ 375$ billion with China. This was the largest imbalance among any set of countries at the time.

China ultimately retaliated with tariffs and restrictions on US imports that included pork, wheat, rice and dairy products. These resulted in the cancelation of orders for nearly 1.1 million tons of soybeans from the US. This equated to nearly $\$ 14$ billion annually (Dobush, 2018) (see Exhibit 2).

\section{Jabil Inc.}

Founded in 1966 by James Golden and William E. Morean, Jabil provided a wide range of solutions in electronics manufacturing services (EMS) as well as diversified manufacturing services (DMS) on a global scale. Its core competencies included intelligent digital supply chain management, sophisticated product design engineering, component procurement, and product safety and reliability testing through manufacturing development expertise. Companies collaborated with Jabil to resolve business needs through specialized services that ranged from systems assembly and regulatory compliance to direct-order fulfillment and configure-to-order services. Industries serviced were extensive and included appliances, capital equipment, data and diagnostics, automotive, consumer lifestyle and wearable technology, computing and storage, defense and aerospace, digital home, networking and telecommunications, healthcare, retail, industrial and energy, enterprise and infrastructure, public sector smart cities, packaging, and printing. Jabil was segmented into five multifaceted divisions: Engineered Solutions Group, Enterprise \& Infrastructure, Nypro Healthcare, Jabil Green Point, and Jabil Packaging Solutions. With more than 100 facilities in 29 countries (see Exhibit 1), Jabil's comprehensive product management services empowered customers to embrace and explore opportunities to optimize growth and profitability while remaining cost effective and solution oriented (Reuters, n.d.). 
Jabil has invested significant time and effort in manufacturing, training and supply chain management. The benefits are huge, and I don't believe we could have achieved the same results as quickly and efficiently. -- Tony Miola, VP, Global Outsource Operations, Xcerra

\section{Corporate Governance and Client Relationships}

Jabil's leadership incorporated a multi-tiered ecosystem that consisted of a collaboration of Chief Executive Officers presiding over each internal division. This created the agility and flexibility of a small, independent business, while it retained the benefits of being a multi-billion-dollar corporation. The mission of each organizational unit was to create value through five key differentiators: Empowered Experts, Accelerated Innovation, Global Manufacturing Agility, Engineering Excellence, and Supply Chain Orchestration. Furthermore, values and practices integrated sustainability as a priority to ensure decisions were made in reducing the company's impact on the environment and natural resources.

Consistent consideration of the interests of all stakeholders in combination with the company's interests was imperative and client relationships remained a paramount priority. Jabil was committed to delivering superb customer service through forward-thinking, knowledge-sharing, problem-solving, and fixed engagement with the exact desires and needs of every client. Building trust and providing support from the ideation stage to mass production was a prominent expectancy (Jabil Inc., n.d.).

"We want to be the brand behind the brand(s)." -- CEO Mark Mondello

\section{Engineered Solutions, Not Services}

Jabil Engineered Solutions Group (ESG) developed solutions that supported five market sectors: Automotive and Transportation, Energy, Industrial and Building, Print and Retail, Smart Home and Appliances, and Defense and Aerospace. ESG provided client-driven solutions which elevated value. This value-driven culture was one of Parker's primary efforts. His aim was to disrupt the status quo in $3 \mathrm{D}$ printing, robotics and large form factor precision assembly.

Parker had worked at Jabil since 1999 and had held the position of Executive Vice President and CEO of the Engineered Solutions Group since 2015. His goal was to create and capitalize on untested markets and transform the landscape of manufacturing. As Parker continued to reflect on his situation, it began to rain, but Parker was never one to pack it up and leave early. He put his jacket on, pulled up his hood and settled in. Jabil was a global enterprise that competed with both much larger companies that surpassed them in size and revenue, and smaller, regional players that sought to make inroads with customers in specific regions. Companies like Taiwan's Hon Hai Foxconn, which had a market capitalization of approximately $\$ 87$ Billion as of FY18, information that he recalled from last week's meeting. However, that was just one competitor Parker had to worry about. He had a list of other companies that could not be overlooked, global and regional companies like Flex, Plexus Corp, Benchmark Electronics, TTM Technologies, Methode Electronics, CTS Corporation, Celestica, Compal Electronics, Pegatron, Quanta, Sanminia Corporation, TPV Technology and Wistron Corporation. Most of these companies had revenues of over $\$ 3$ billion. Although this was not an all-inclusive list, the magnitude of scale clarified the scope for Parker. This underlined the hyper-competitive nature of the space, which was one of his main obstacles.

Parker knew his challenge was not just about competitors; he had to identify other system constraints and mitigate or control risk exposure. He also had to forecast and strategize how to gain or maintain market share, customers and retain profits when tariffs were enacted. The rain started to let up and the sun peeked out for a few minutes. Parker started to think about his customer relationships. While business was good, 
the question was how would Parker and his team navigate the seas of constraint and calm his customers' nerves during the uncertain future?

\section{Leveraging Strategic Capabilities}

A sudden forceful tug on Parker's fishing line caused him to tightly grab the pole and immediately begin reeling in his catch. Just before his excitement could sink in, the line went loose, and Parker lost his catch. He rummaged through his tackle box and found a different hook he believed would work the next time around. Parker always knew that patience, persistence, and commitment to sound fundamentals were critical in determining next steps, whether he was fishing or making business decisions. He thought about how Jabil's key differentiators--capabilities and advanced tools--would help the company and its customers navigate the uncertain business climate that would impact relations with China.

\section{Manufacturing}

Parker was committed to Jabil's vision of empowering customers through speed, flexibility, and efficiency gained by analyzing and executing specific manufacturing scenarios. He understood that Jabil's capabilities included approximately 42 million square feet manufacturing space in 29 countries across North and South America, Europe, the Middle East, Africa and Asia. He believed in this global manufacturing agility, and its structure and strategy were set to ensure Jabil's business relevance, competitiveness, and success in a world of unrelenting change. The question was where to start? A fairly large portion of Jabil's products and components were manufactured in China. Parker decided to group these products and components into three distinct categories and analyze available solutions on a category by category basis.

\section{Categories of Products}

Products manufactured by Jabil in China were essentially divided into three different categories:

Products that were manufactured globally. Jabil had the ability to flex production between manufacturing sites in other regions with similar capabilities. Parker evaluated and analyzed the products affected and compared the total landed cost for these products with other regions where those products were qualified.

Products that were manufactured in a large centralized operation in China but sold globally. Parker contemplated a potential regional shift. This would be the time these decisions would be accelerated. For example, if $20 \%$ of the demand was in Europe, $50 \%$ was in America and 30\% was in China, these products would be moved to each region respectively.

Products that were manufactured in China and predominantly sold in Asia. Parker believed that new tariffs could force Jabil to relocate these products to a non-affected region. These products would be transferred on a short-term basis and then relocated back to China if the imposed tariff climate changed. This would mean that Jabil and the customer would incur significant transfer and set up costs.

Alternatively, both could come to a legal agreement to continue the operations inside China and incur the imposed tariff cost. However, the agreements in place would state that Jabil would take the initial financial risks, and the customer would eventually pay the premium per product unit through amortization. 


\section{China, Huangpu}

Parker recalled a presentation when he was on site in Huangpu back in December 2017, which showed that approximately 22 million square feet of Jabil's available facilities were in China, with Huangpu being one of the largest manufacturing sites for Parker's division with over 1.7 million square feet. Jabil's Huangpu manufacturing facility included industries such as energy generation, efficiency and infrastructure, white goods, heavy industries, mobile devices, and printing. Some examples of the products manufactured were power converters and inverters, smart metering systems, printers, and automotive control modules. This manufacturing site was in China's first and largest Economic and Technological Development Zone in Guangzhou and provided competitive cost and superior quality. However, with the first list of tariffs being identified and effective on July 6th of 2018, Parker realized that a fair amount of his divisions' China-manufactured products were affected by the new duties. Parker wanted to build a strategy for the three different categories of products manufactured in China so that he had solutions readily available to his customers, regardless of the types of products they needed (Scarbrough International, Ltd., 2018).

\section{Supply Chain Network Optimization}

Parker realized he faced various challenges in each of the categories due to Jabil's position in China, however, he combated these issues head on and utilized several tools to evaluate alternative solutions. One of the nine tools at Parker's disposal within Jabil's InControl Solution was the Supply Chain Network Optimization (SCNO) analysis tool (see Exhibit 2). Like Jabil's well known InControl application that drove risk mitigation and decision support, the SCNO analysis offered an evaluation of site alternatives. This analysis was used to portray a total delivered cost for a product which utilized several influential factors, such as bill of materials, manufacturing costs, freight and duty fees, and inventory. This model could evaluate several locations simultaneously to determine the total delivered cost and help Parker's team and their customers determine the best path forward to reduce risks and mitigate the tariff impact.

The supply chain network optimization tool was a great indicator of the advantages and disadvantages of operations that could be moved to non-tariff sanctioned regions. It also helped Jabil and its customers make critical business decisions that would impact the success of the business. This tool not only acted as a one-stop shop to understand risks, it also helped Jabil and its customers to agree on price negotiations. Jabil would either choose to increase the price to the client, or as a last resort, Jabil and the client would agree to diminished profit and "ride the wave" until the tariff climate eased.

\section{Compliance}

The decision would not be as simple as increasing the price to the client as there were numerous Manufacturing Service Agreements (MSA) in place that would require mutually agreed upon modifications. The Electronic Manufacturing Services industry had a very competitive landscape, and not only did companies battle for capabilities, resources, and locations, they also battled to provide the best commercial terms and compliance regulation understandings that could ultimately benefit their customers. Parker was aware that Jabil's supply chain solutions and expertise would give Jabil the best option to be profitable in times like these, however, he also knew that he had to be sensitive to his customer's expectations and Jabil's ability to deliver as promised.

Commercial terms were set forth by the business leaders, while compliance standards were regulated and enforced by the World Customs Organization; and while these efforts did not contribute to the manufacturing directly, they supported the footprint to the customer relationship and guidelines that protected the relationship and/or product. Outside of the commercial terms, there were uncontrollable forces that could impact business relationships, none of which had been more impactful than the tariff 
sanctions placed on China. Parker knew that if he were going to build sustainable and lasting relationships with his customers, he must provide a deep understanding of the Harmonized Tariff Schedules, better known as HTS codes, that could derail his business relationships. To do this, Parker had to contact his head of compliance to understand the impact that tariffs would have on his customers' products. HTS codes essentially classify products that are being imported or exported and assign duty rates to those codes.

\section{The Decision}

As a result of the recent changes in the geopolitical landscape that impacted Jabil, Parker and his customers faced immediate impact on a significant portion of products sold into the US market. Jabil, as with many other manufacturing companies, faced a constantly changing environment. The uncertainty could easily cause other organizations to make rash decisions as they reacted to the political and economic environments affecting global manufacturing organizations. Jabil however had created an organization that had the size, scale, and capability to weather these changes and use them to enhance and showcase its competitive advantages. The environment provided a key opportunity for Jabil to leverage proactive statistical modeling and sound decision support to evaluate possible decisions, their outcomes and alternatives that could benefit customers.

Parker believed that with the help of the supply chain organization, as well as the legal organization, his team had the ability to sustain disruptions without hesitation or concern. Jabil had developed a set of disruptive supply chain tools for such circumstances that would enable a sound evaluation of the business landscape, allowing Parker to focus on the company's long-term goals. What was the right combination of solutions that would introduce Jabil's competitive advantages? How could Jabil use the shifting seas to demonstrate its capabilities to its customers? What course would Parker chart to navigate his team through the impending rough seas? He knew he had the right vessel, the right crew, and the right tools, and that it was his job to lead the ship to calmer waters.

\section{Manufacturing}

With respect to manufacturing, Parker had identified three plausible options.

1. The first was complete all manufacturing in China which would be subjected to the $25 \%$ tariff when the products were imported into the United States. This option would require Parker and his team to either absorb the entire $25 \%$ tariffs or come to an agreement with their customers on the price increase due to the tax imposed on the products.

2. The second option was a combination of partial manufacturing. The product would start in China then be transferred and completed in locations that were close to the end user. This option would offer several benefits including reduced transportation costs and a reduction in exposure to US and other tariffs. This option was not without drawbacks, however. Among these were: increased manufacturing costs that might not be fully offset by transportation savings and increased capital expenditure where existing facilities required renovation or expansion.

3. A third option was to move some of the manufacturing facilities to territories not affected by tariffs and complete manufacturing outside of China. Not only would this option eliminate the $25 \%$ tariff imposed on the products, but it would also allow Jabil to reduce dependence on manufacturing located in China as well as expand operations in countries where tariffs are not 
being imposed on products manufactured and shipped. However, these moves would have substantial capital costs as well as increased costs in labor, capability challenges and other plantrelated expenses.

\section{Compliance}

From a compliance standpoint, to combat the potential for excessive duty implications, Parker knew that he had two opportunities to mitigate any potential risks. The first effort was to use Jabil trade compliance to determine if there were reclassification opportunities on products to help minimize the impact of the duties. In doing so, trade compliance would need a full understanding of the components and functionality of the products. This could create hundreds of thousands of dollars in savings by reducing the duty rate. However, if these reclassification efforts were unsuccessful, Parker would need to propose to his customer that they create a two-site build that could essentially erase the duty rates. This would mean that although the build took place in China, Jabil would then ship the unfinished goods to unsanctioned locations for final assembly and/or test, and then ship the finished goods to the United States. Parker knew that his next actions could be impactful to his current customer relationship and could be a valuable opportunity for both parties to drive the best possible outcome.

\section{Do Nothing}

Given the changing sociopolitical and economic environments, Jabil could elect to do nothing and "rideout" the storm. Since Jabil is a large organization with considerable economies of scale and a diversified portfolio of divisions and manufacturing locations, Jabil may not see the tariffs as a significant threat to their business. If the trade and tariff wars were short lived, then Jabil could avoid the expenses associated with facility and plant moves or long and complicated reviews. The steady approach could signal the confidence that the leadership has in the organization and its strategic positioning. However, since the future of the trade war was uncertain, to do nothing could leave Jabil behind the competition if the competition moved their manufacturing to other regions. As the competition made moves to other regions, it could drive up capital costs for the followers to those areas.

\section{The Hybrid Approach}

Parker also thought about a hybrid approach as well. He could also combine one or more of the options listed above to create a solution that provided something greater than any individual solution mentioned.

\section{Summary}

As Parker docked his boat, he reflected on another successful trip. Much like his work with Jabil, he never knew exactly what he would encounter when he lost sight of the shore, but he had confidence in his equipment's and his team's ability to navigate uncertain seas against the best in the world. Where others feared rough seas, Parker saw opportunity for adventure that would deepen the bonds that the company shared with its customers. It was time to change out of his fishing clothes and get back down to business. Parker relished the opportunity to get back to work competing on a global scale. There was just one question that remained: Where should Jabil go from here? 


\section{References}

Dobush, G. (2018, July 4). Here's what will happen when China and U.S. tariffs take effect Friday. Fortune. Retrieved from http://fortune.com/2018/07/04/china-us-trade-war-tariffs-friday/

Jabil Inc. (n.d.). Empowering brands who empower the world. Retrieved from https://www.jabil.com/

Leong, K. C. (2015, May 06). Jabil-The manufacturing giant you've never heard of-steps out of the shadows. Fast Company. Retrieved from https://www.fastcompany.com/3045936/jabil-circuit

Reuters, (n.d.). Jabil Inc. (JBL) company profile. Retrieved from https://www.reuters.com/finance/stocks/companyProfile/JBL

Scarbrough International, Ltd. (2018, July 31). Trump tariff timeline: A timeline of tariffs affecting U.S. goods. Retrieved from https://www.scarbrough-intl.com/trump-tariff-timeline/

Staff, I. (2017, December 18). Tariff. Retrieved from https://www.investopedia.com/terms/t/tariff.asp

\section{Acknowledgements}

We would like to thank the executive leadership at Jabil Inc. for participating in this case. Their willingness to share their perspectives and insights on the tools they used for critical, global decision making in a highly complex business environment was extremely helpful. 


\section{Biographies}

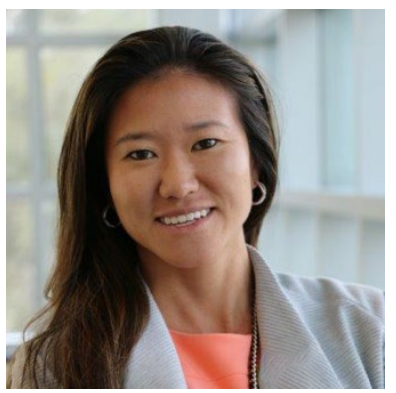

Jean Chua's golf scholarship in college has paid off. She has been on the LPGA tour for the past eight years, but now knows that there's more to life than getting to the green in two. As a professional golfer, her days are not only spent training and competing, but marketing as well. So, she wants to get a better handle on the business side of her career.

"Business has an impact in almost every walk of life," she says. She recently joined Jabil and is currently the chief of staff to Jabil's EVP and CEO of the Engineered Solutions Group. In this role, she oversees strategic planning for all the sectors within the division and works directly with executive leaders to organize and implement the annual strategic development process for the division. Chua graduated from Wake Forest University in Winston-Salem, North Carolina, in 2009 with a bachelor's degree in Mass Communications.

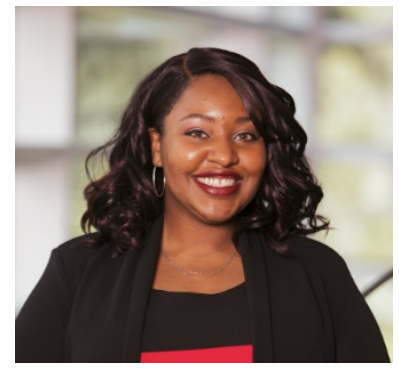

Stacy-Ann Henry is a service supervisor with GEICO insurance company. She manages, trains and develops teams of automobile insurance counselors. She has nine years' experience, the last six of which have been with GEICO in a management role. She has the highest insurance license available from the state of Florida and assists with the day-to-day operations in one of the company's largest profit centers.

She also supervises GEICOs customer-service department and is called upon to handle escalated consumer conflicts, monitor performance and information accuracy, and instruct co-workers through problem solving and on-the-spot training. She also serves as the diversity training facilitator with her company and conducts regular training courses to foster constructive dialogue about diversity. Henry graduated from the University of Florida in Gainesville in 2009 with a bachelor's degree in Business Management with a minor in Leadership.

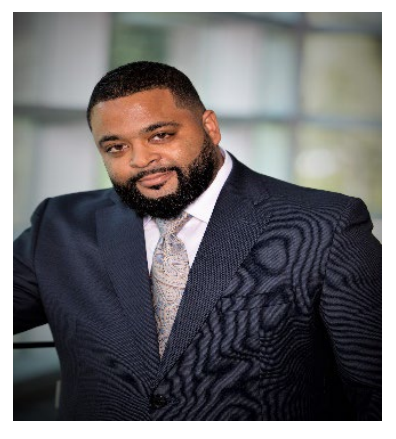

Darryl Johnson is the Chief Operations Officer with Cardeaus Solutions. He is a proven visionary executive with more than 24 years in government, health care, IT management and operations business segments. He continues to blaze a path of success with his passion to coach, mentor and create value. His obsession to tackle wicked problems drove him and his partner to establish Cardeaus Solutions, a consulting company which focuses on streamlining processes, building value and improving customer experiences.

His success as an entrepreneur and in the United States Air Force gives him a highly desired level of experience. He has held several other positions prior to the launching of Cardeaus Solutions. He was a deputy clinical operations officer and advised clinical leaders on operational performance. Prior to his last military assignment, he was director of quality/process improvement and the deputy chief information officer for two Air Force clinics at MacDill Air Force Base in Tampa. Johnson holds several IT, project management, security, compliance and a Lean Six Sigma Black Belt certifications. He received his bachelor's degree in Computer Information Systems Management from Park University in Parkville, Missouri, in 2010. 


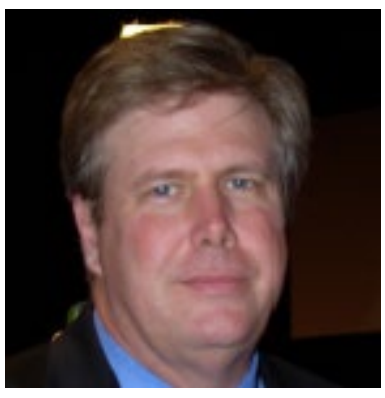

Jerry Mallory is an accomplished senior executive with more than 30 years of success spanning the food and beverage, hospitality, environmental services, logistics and delivery industries. Leveraging his experience as a chef, instructor, manager and director committed to driving results by increasing operational efficiencies, he has proven to be a valuable asset for Sodexo. His broad areas of expertise include client relations, training, operational management, budgeting, food safety and leadership.

Throughout his executive career, he has held a number of leadership positions. Currently, he serves as general manager with Sodexo-Moffitt Cancer Center in Tampa. Here he directs a cultural transformation with food service efficiency and effectiveness by increasing top-line revenue by 54 percent year over year. Mallory graduated from the University of South Florida in 2013 with a bachelor's degree in Business And Industrial Operations and has earned a Lean Six Sigma Green Belt certificate from the Terry College of Business in the University of Georgia in Athens, Georgia.

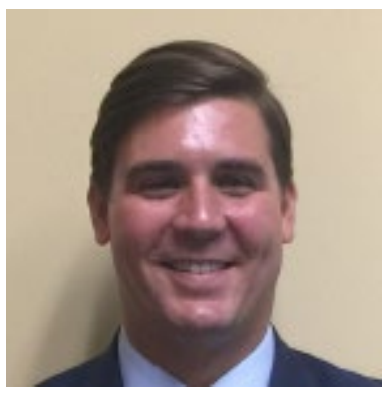

Justin Smith is an engineering and business consultant that delivers solutions to a variety of technical companies in the design, construction, real estate, insurance and legal services markets. In this role, he leads cross-functional and geographically distributed teams in pursuit of operational, business development and project-specific goals. In addition to functioning as an inside technical consultant for various teams throughout the country, Smith assists firm leaders in developing strategic plans for service expansion, geographic expansion and systematic business development programs.

Smith hopes the USF Executive MBA program will help elevate his business skills and give him new perspectives into networks outside the engineering and construction industries where he primarily works, in addition to improving the quality of and efficacy of services that he delivers to his clients. Smith earned a bachelor's degree in Civil Engineering from Southern Methodist University in Dallas, Texas, in 2008, and a master's degree in Civil Engineering from the same university in 2009. $\mathrm{He}$ is a licensed professional engineer in more than 25 states throughout the country.

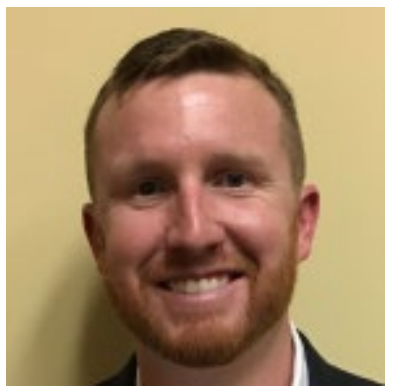

Raymond Wilhite works for a commercial construction company specializing in restaurant renovations and facility work. He is a senior project manager for Regions Facility Services, with corporate offices in Brooksville, Florida, and satellite offices in Lexington, Kentucky and Atlanta. Wilhite recently was tasked with expanding RFS West and is currently establishing an office in Waco, Texas, to better serve its central and West Coast customers

$\mathrm{He}$ is responsible for budgeting, client relations and project profitability and currently has an 11-person team reporting directly to him. He hopes an Executive MBA will boost his understanding of entrepreneurship, leadership and business acumen. He also seeks to meet other professionals and executives in the program who will provide their own level of experience and education. Wilhite graduated from the University of South Florida in 2008 with a bachelor's degree in Finance. 


\section{Exhibit 1: Jabil Company Review}

\section{BUILT ON A SOLID FOUNDATION}
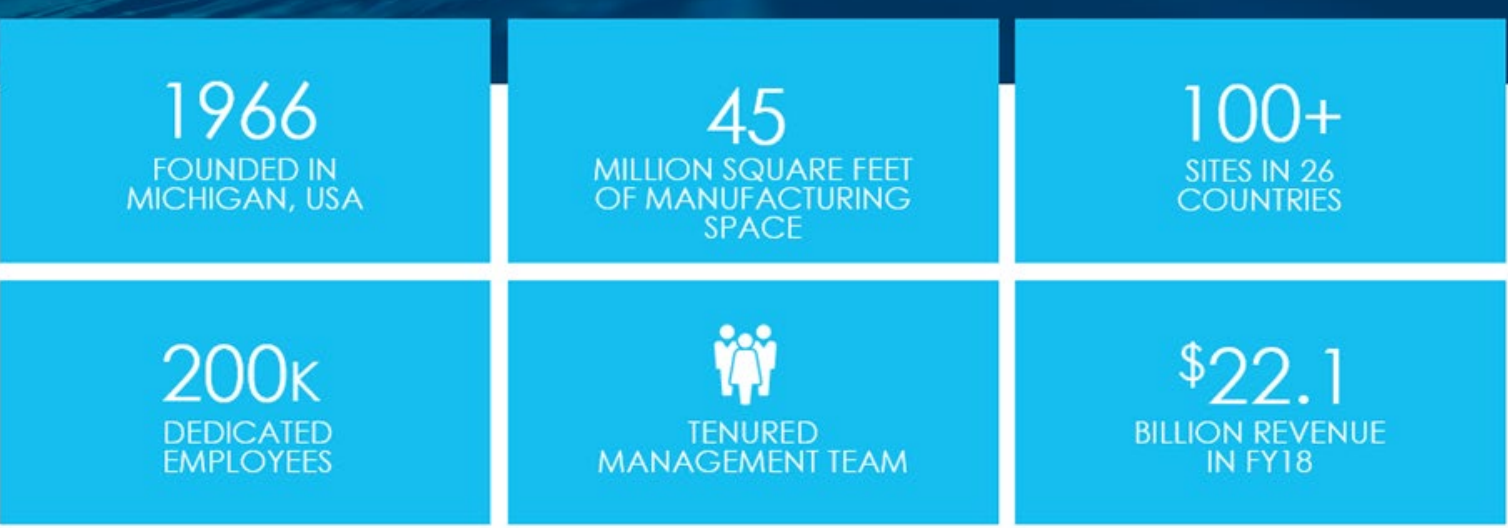

\section{GLOBAL OPERATIONS ENABLE} LOCALIZED MANUFACTURING

\section{JAEIL}

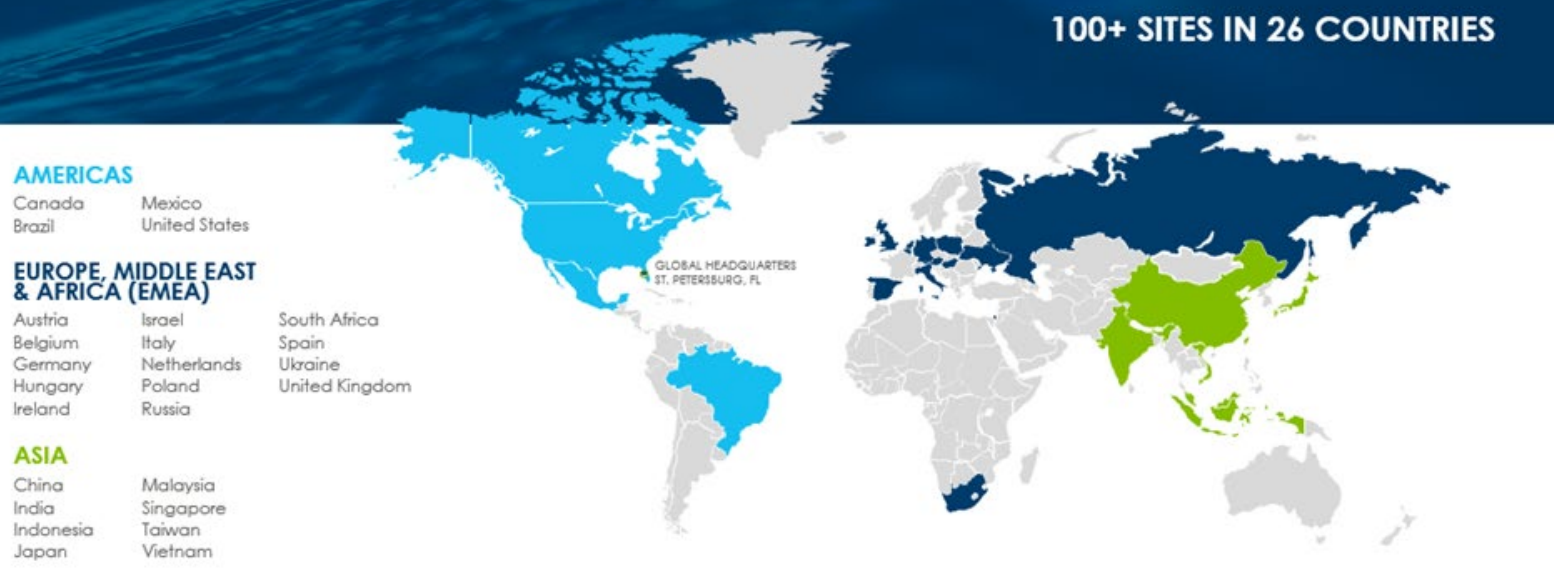




\section{JABIL}

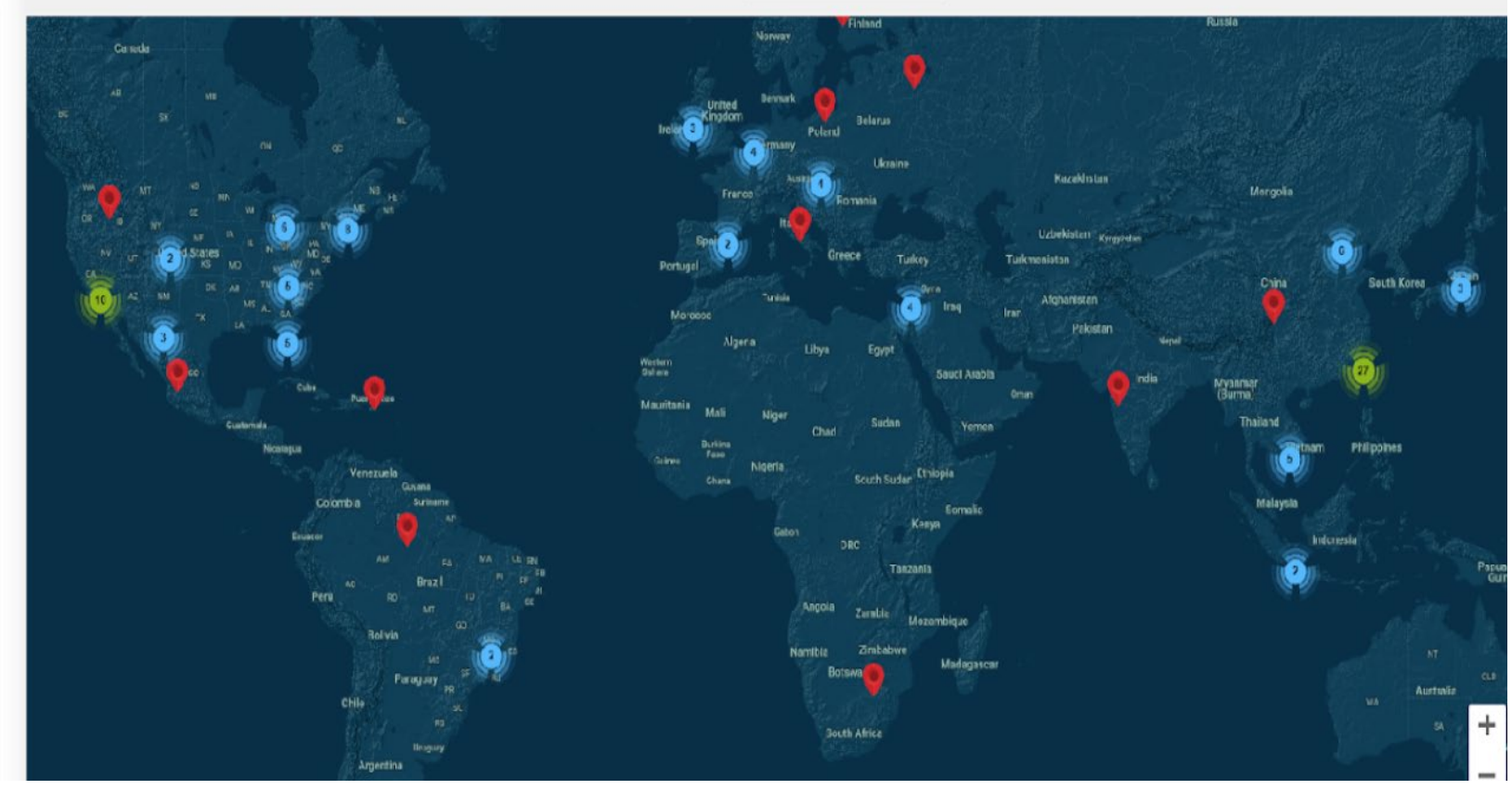

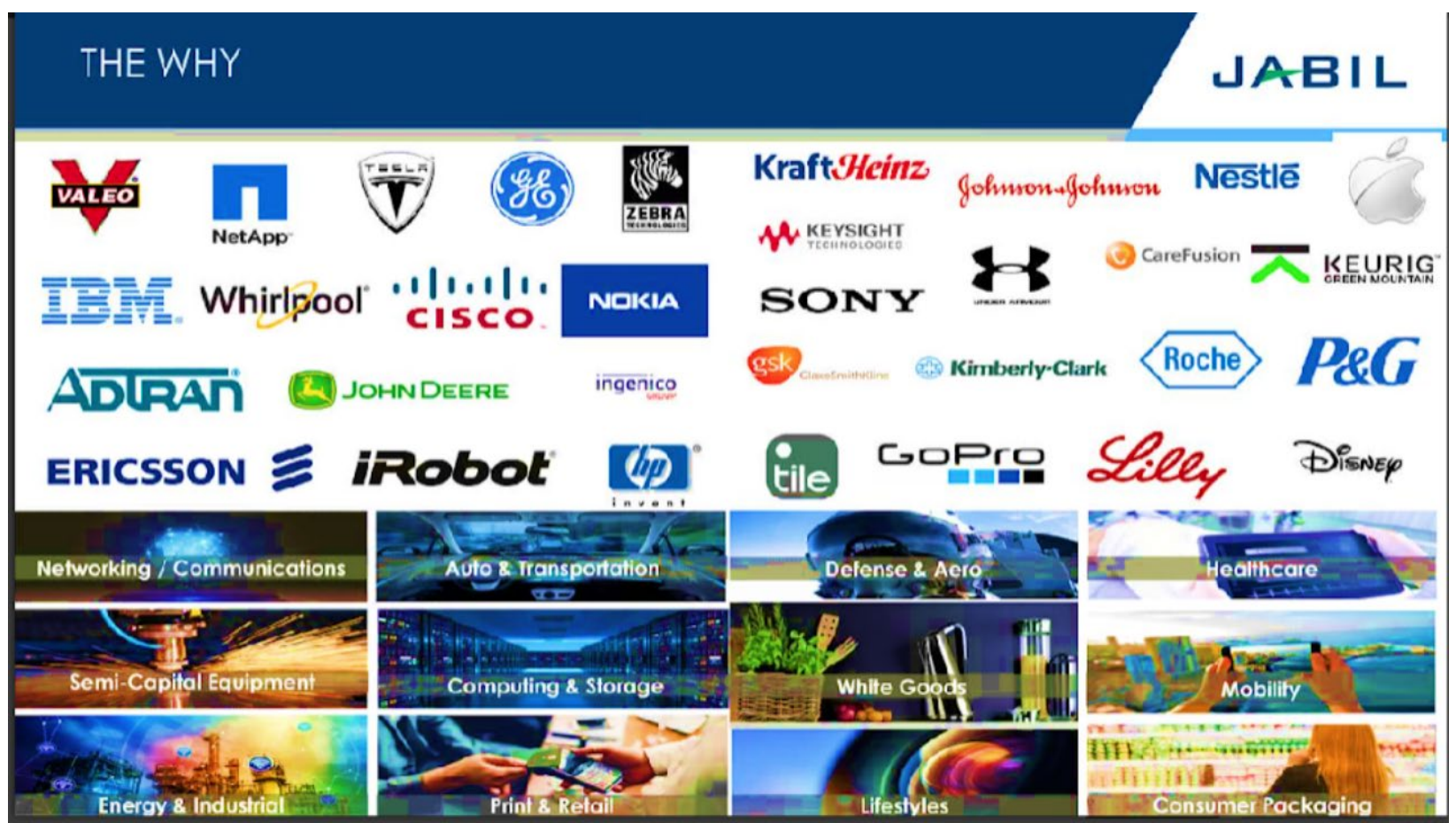




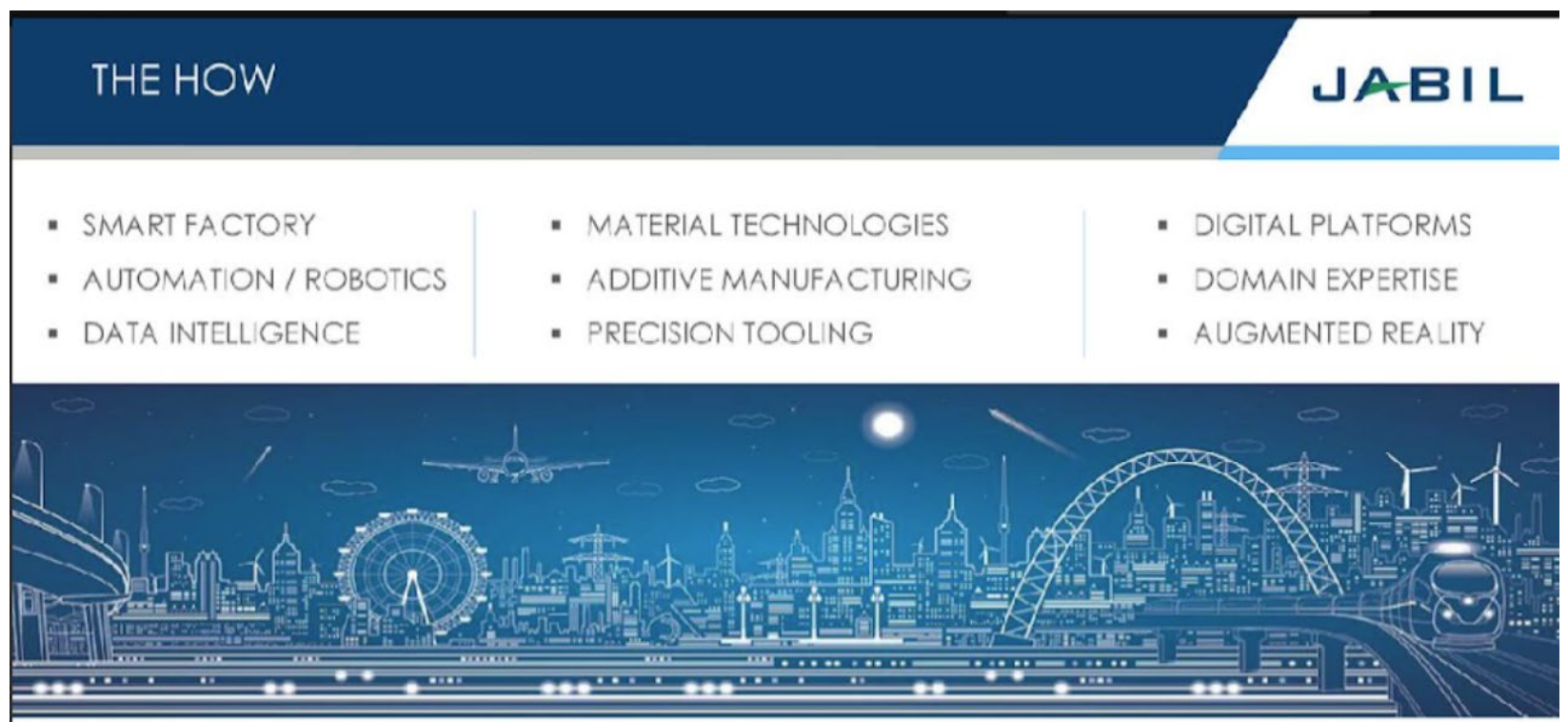

Our Sizable Scale, Our Disciplined Approach, Our Autonomous Market-facing Structure

\section{THE WHAT}

\section{JABIL}

\section{Fiscal Year 17}

- Our DMS Segment grew 9\% year-on-year

- Our EMS Segment expanded core margins by 50 bps year-on-year

- The team delivered Core EPS of $\$ 2.11^{*}$ (13\% growth over FY16)

- Strong Cash generation of $\$ 1.25 b b$

- Returned $\$ 370 \mathrm{~mm}$ in Capital to Shareholders

Most Importantly, was the Composition of these Results

"Please see Non-GAAP reconclation on pg. 36 of the form 10-k for the year ended August 31, 2017

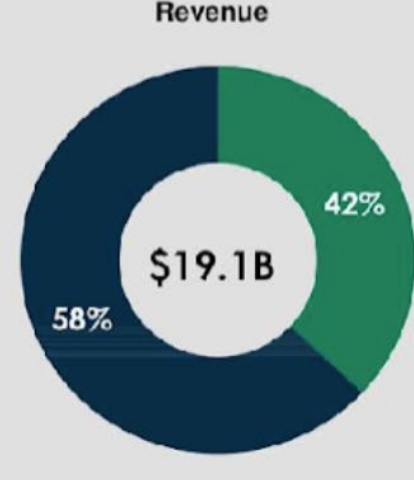

FY2017

n Diversified Manufacturing

- Electronics Manufacturing 


\section{THIRD QUARTER 2018 SEGMENT RESULTS}

- Diversifled Manufacturing Services (DMS)

- Net Revenue increase of $36 \%$

- Core margin* (non-GAAP) of 1.3\%

- Electronics Manufacturing Services (EMS)

- Net Revenue increase of $12 \%$

- Core margin* (non-GAAP) of $3.8 \%$

- Total Company

- Net Revenue increase of $21 \%$

- Core margin* (non-GAAP) of $2.8 \%$

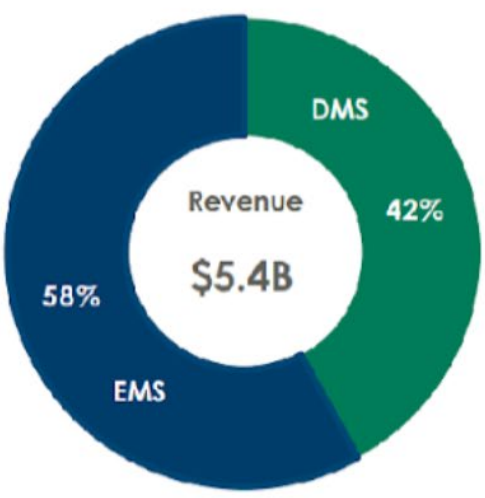

- Core margin = Core operating income divided by net revenue
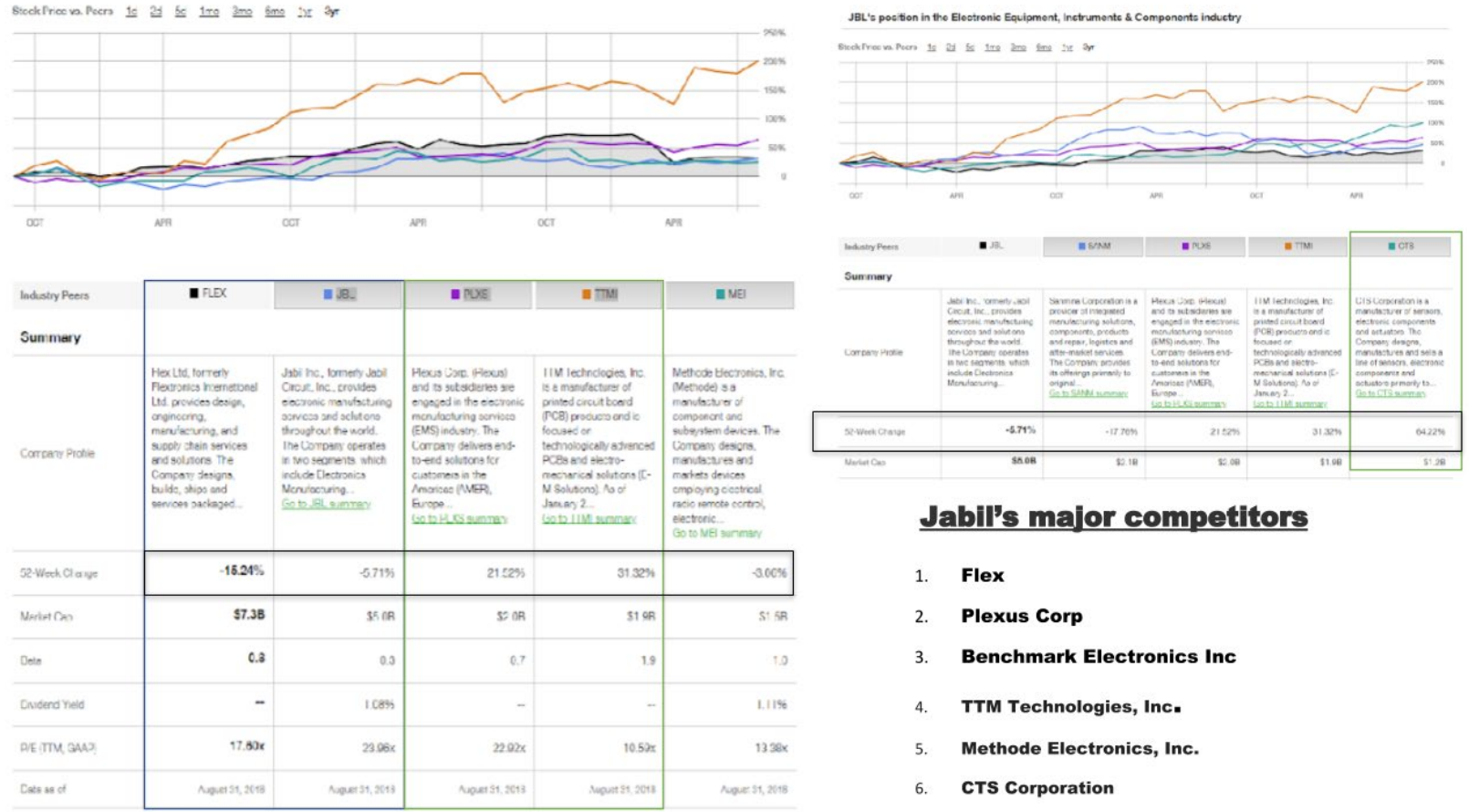

\section{Jabil's major competitors}

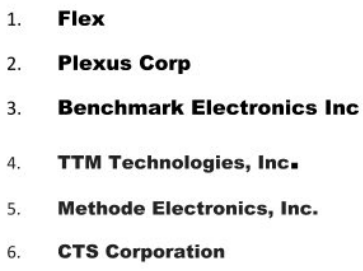

Source: Company documents 
CHUA, HENRY, JOHNSON, MALLORY, SMITH, WILHITE

Exhibit 2: Jabil Supply Chain Network Optimization (SCNO)

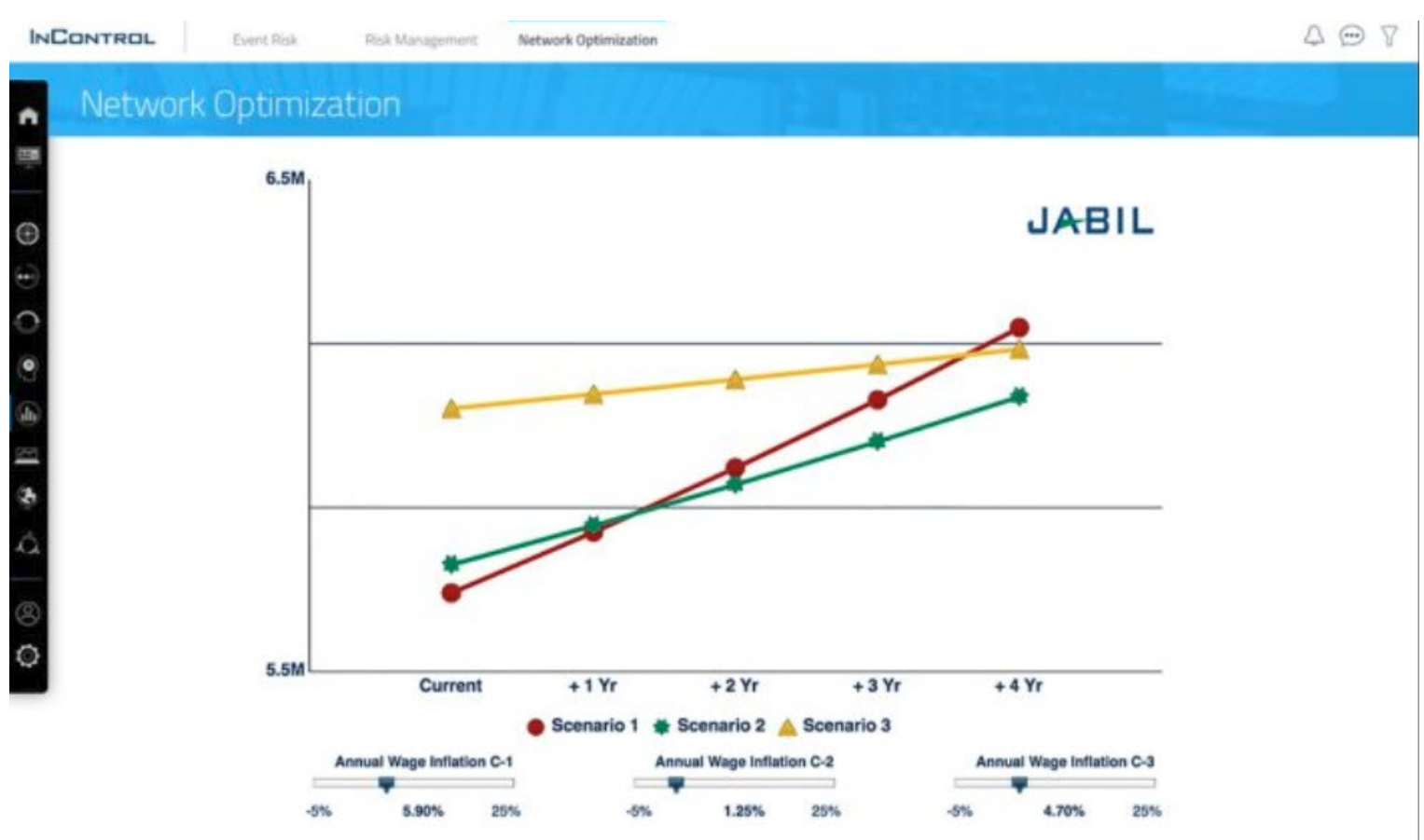

JABIL

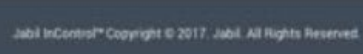

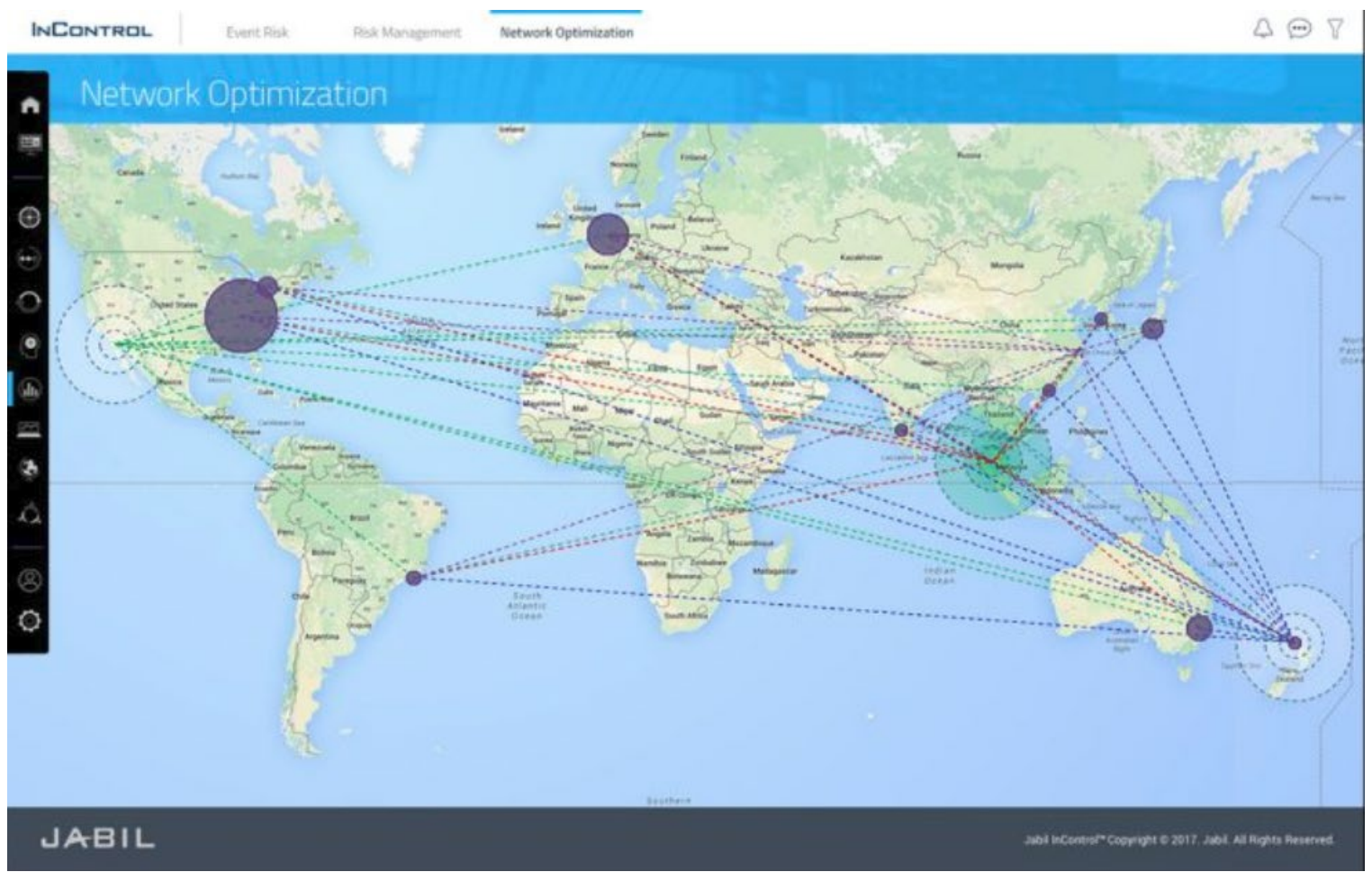

18

Volume 4, Number 10, 2019 


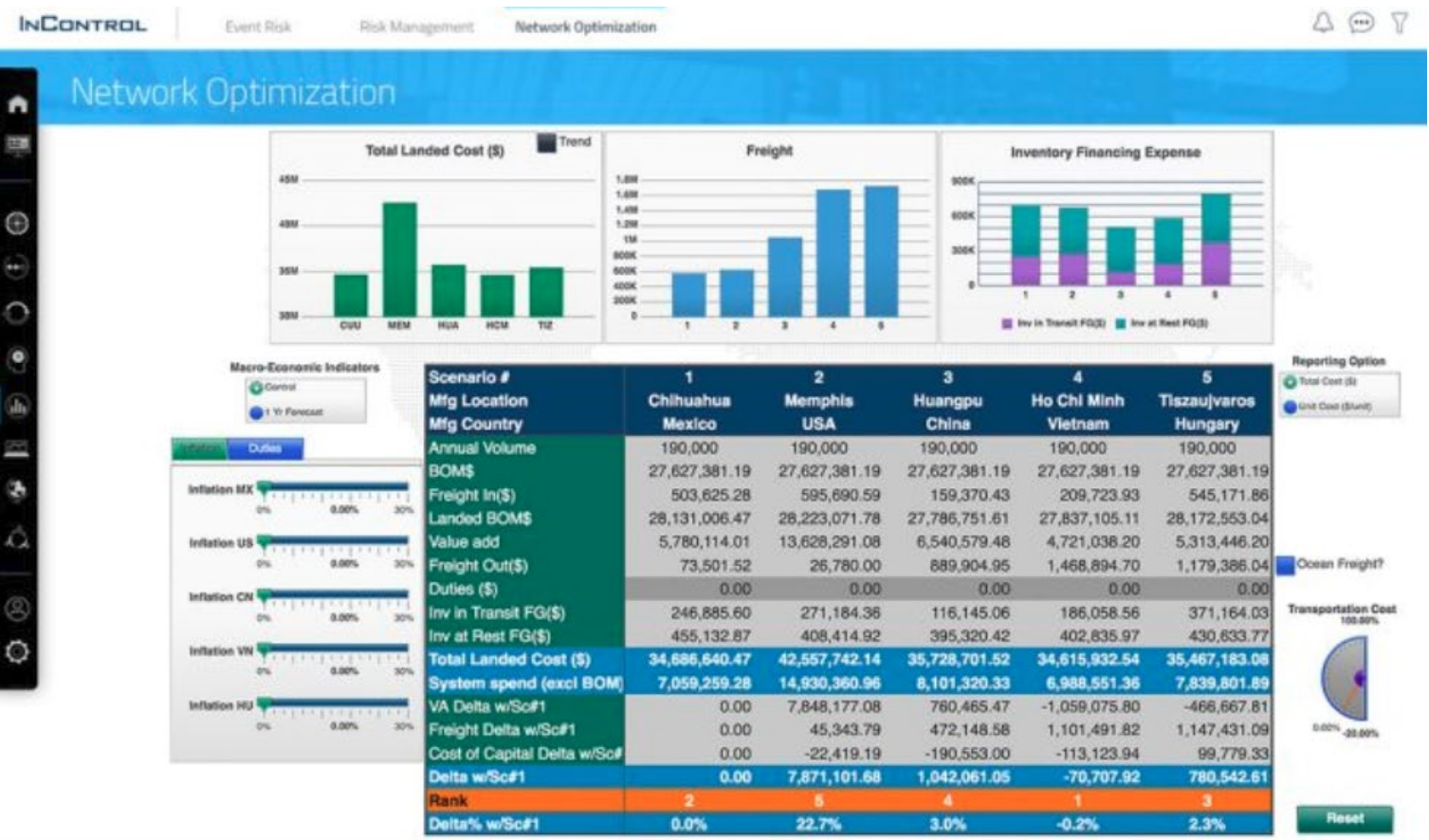

\section{T3 Policy Readiness Assessment Trade, Tax and Tariff Guidance for a Changing World}

\section{JABIL}

The recent trend in increased nationalism may trigger significant economic policy adjustments, including re-negotiating or withdrawing from longstanding trade deals, new tariffs attempting to establish 'fair and balanced' trade, and the overhaul of tax codes. These changes could lead to complex shifts that will significantly affect current supply chains.

To mitigate the risks associated with this climate of uncertainty, many executives are now reassessing their global supply chain strategies from the bottom up, considering new models for:

- Flexibility - by manufacturing closer to end-markets, U.S. companies can become more responsive to American demand. Should policy changes occur, first movers will enjoy increased flexibility while laggards scramble to update their supply chain strategies.

- Cost - securing alternative suppliers, locations, and materials would be required to mitigate rising costs. A proactive approach could minimize these costs many times over.

- Risk - closer proximity to end-markets will decrease risk in manufacturing and transit. However, moving a supply base from Asia to the United States could necessitate depending on single-source suppliers, leading to a higher overall risk profile.

Policy Readiness, Brought to You by Jabil and PwC

To help business leaders prepare their supply chains for the unexpected, Jabil's Intelligent Digital Supply Chain (IDSC) group has partnered with PwC to provide a comprehensive supply chain assessment designed to uncover the impacts associated with various policy shifts. This rapid optimization assessment measures the resiliency of your current supply chain and prescribes resolution strategies for a variety of potential scenarios.

Using sophisticated segment benchmarking capabilities, a T3 Policy Readiness Assessment provides U.S. companies with:

a Actionable, fact-based scenarios reflecting changing global trade and tariff policies

- Realigned supply chain scenarios that factor in supply base, sourcing, and logistics options to mitigate risk

- Manufacturing and distribution footprint impact assessments based on fluctuations in trade agreement policies

This understanding significantly improves fact-based decision making, enables faster responses to changing environments, and dramatically enhances communications with stakeholders and partners. 


\section{Built for Practitioners by Practitioners}

\section{JABIL}

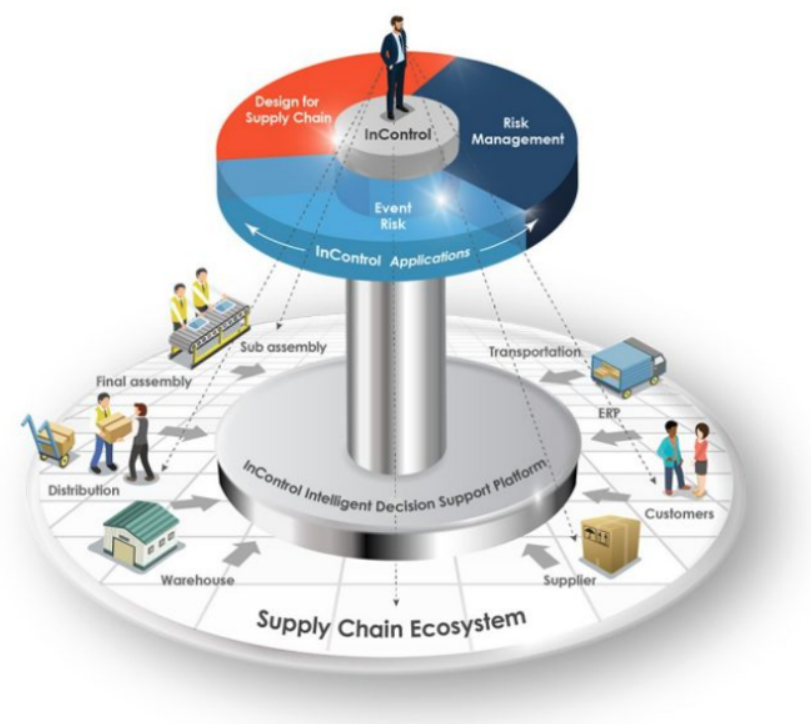

Jabil InControlTM is a intelligent supply chain decision support solution. A combination of a sophisticated multi-tenant platform that ingests and analyzes data from a variety of sources across the enterprise and sophisticated applications delivering unmatched visibility, collaboration, and risk management across the entire supply chain ecosystem. Enabling businesses to compete at the speed of commerce in the new digital economy.

\section{Intelligent Decision Support}

The Jabil InControl ${ }^{\mathrm{TM}}$ platform provides visibility, analytics and collaboration across the entire supply chain. It is an intelligent supply chain platform with Active Intelligence running specialized applications of sophisticated analytics, a massive knowledge base, and cognitive analytics to manage and process structured and unstructured data. The Jabil InContro|'TM platform serves 3 supply chain applications for Event Risk, Design for Supply Chain and Risk Management.

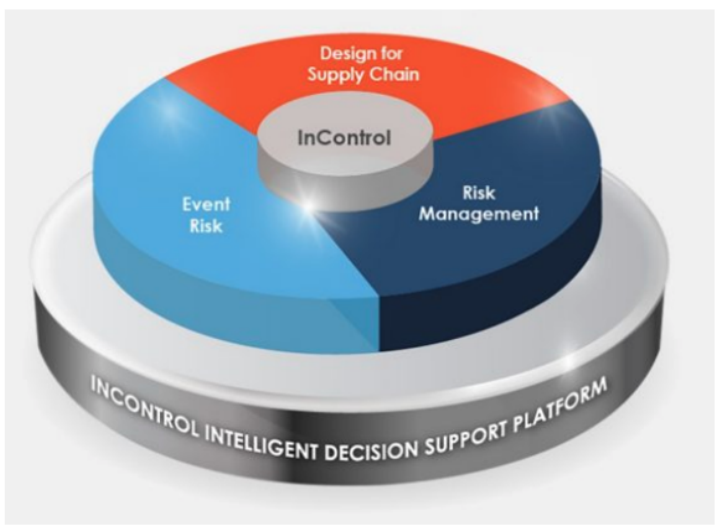

Source: Company documents 